\title{
POLIEMBRIONIA E NÚMERO DE SEMENTES POR FRUTO DE QUATRO CULTIVARES DE TANGERINEIRA
}

\author{
POLYEMBRYONY AND NUMBER OF SEEDS PER \\ FRUIT OF FOUR MANDARIN CULTIVARS
}

\author{
Lia Rosane Rodrigues ${ }^{1}$ Ana Lúcia Cunha Dornelles ${ }^{2}$ Maria Teresa Schifino-Wittmann ${ }^{3}$
}

RESUMO

Quatro cultivares de tangerineiras foram caracterizados quanto ao número de sementes por fruto e quanto à poliembrionia, três dos quais são usados como genitores no programa de melhoramento genético do Departamento de Horticultura e Silvicultura da Universidade Federal do Rio Grande do Sul. Coletaram-se frutos de plantas da coleção de citros da Estação Experimental Agronômica, em Eldorado do Sul, RS, cujas sementes foram retiradas e contadas. Em câmara estéril, os embriões foram extraídos das sementes e inoculados em meio de cultivo MT (Murashige \& Tucker, 1962), permanecendo por 49 dias a $26 \pm 3^{\circ} \mathrm{C}$ sob fotoperíodo de 16h. As tangerineiras Caí, Montenegrina (Citrus deliciosa Tenore), Poncã (C. reticulata Blanco) $e$ King (C. nobilis Loureiro) produziram, em média, 16, 14, 8 e 24 sementes viáveis por fruto, respectivamente, contendo um número médio de 5,7, 5,7, 7,7, e 3,2 embriões por semente. A produção de sementes monoembriônicas foi baixa, exceto no cultivar King, que apresentou $20,4 \%$ das sementes com apenas um embrião. Registrou-se a ocorrência de embriões albinos, que constituíram uma parte ou a totalidade do conteúdo de algumas sementes. De modo geral, as espécies apresentaram diferenças significativas quanto às características estudadas. As similaridades observadas entre os dois cultivares de $\boldsymbol{C}$. deliciosa reforçam a hipótese de Montenegrina ter se originado de Caí.

Palavras-chave: Citrus spp., tangerinas, sementes, apomixia poliembrionia, cultivo de embrião.

\section{SUMMARY}

Four mandarin cultivars were characterized for seed number per fruit and polyembryony, three of them are used as parents in the Departamento de Horticultura e Silvicultura Universidade Federal do Rio Grande do Sul citrus breeding program. Mandarin fruits were sampled from the Experimental Station citrus collection, in Eldorado do Sul, RS, and their seeds

\begin{abstract}
were extracted and counted. In esterile chamber, the embryos were excised from seeds and cultured in vitro on MT medium (Murashige \& Tucker, 1962), at $26 \pm 3^{\circ} \mathrm{C}$ with a $16 \mathrm{~h}$ photoperiod. The mandarin cultivars Caí, Montenegrina (Citrus deliciosa Tenore), Poncã (C. reticulata Blanco) and King (C. nobilis Loureiro) had an average of 16, 14, 8 and 24 viable seeds per fruit, respectively, and 5.7, 5.7, 7.7 and 3.2 embryos per seed. Monoembryonyc seed production was low, except in King cultivar, which had $20.4 \%$ of monoembryonic seeds. Albine embryos were also detected, which were part or total content of some seeds. In general, the species showed significant differences in relation to the studied traits. The similarities between the $\boldsymbol{C}$. deliciosa cultivars are strong evidences for the hipotesis that Montenegrina is originated from Caí.
\end{abstract}

Key words: Citrus spp., mandarins, seeds, apomixis, polyembryony, embryo culture.

\section{INTRODUÇÃO}

O fruto dos citros é uma baga típica chamada hesperídio, na qual se pode distingüir o exocarpo ou flavedo, o mesocarpo ou albedo e o endocarpo, constituído de lóculos, onde estão as sementes, próximas ao eixo central e entre as vesículas de suco (AGUSTI et al., 1995). O número de sementes que constitui o fruto é determinado por fatores genéticos e ambientais (FROST \& SOOST, 1968), sendo uma característica específica de cada cultivar.

O número de sementes por fruto pode afetar o tamanho do fruto em alguns cultivares. FROST \& SOOST (1968) registraram correlações significativas entre tamanho do fruto e número de

${ }^{1}$ Engenheiro Agrônomo, MSc., Faculdade de Agronomia, Universidade Federal do Rio Grande do Sul (UFRGS).

${ }^{2}$ Engenheiro Agrônomo, PhD., Professor do Departamento de Horticultura e Silvicultura, Faculdade de Agronomia, UFRGS. Av. Bento Gonçalves, 7712,91501-970, Porto Alegre, RS. E-mail: alcunha@ vortex.ufrgs.br. Autor para correspondência.

${ }^{3}$ Biológo, PhD., Professor do Departamento de Plantas Forrageiras e Agrometeorologia, Faculdade de Agronomia, UFRGS. 
sementes do fruto, a partir do trabalho de diversos pesquisadores, indicando que frutos com maior número de sementes adquirem maior tamanho.

Atualmente, a produção abundante de sementes em cultivares copa de citros, principalmente naqueles destinados ao consumo de mesa, é uma característica indesejável sob o ponto de vista comercial, pois a demanda por frutos sem sementes tem aumentado, principalmente no mercado internacional.

A grande maioria dos cultivares cítricos produz sementes poliembriônicas devido ao forte potencial embriogênico do tecido nucelar do ovário, circundante ao saco embrionário, que normalmente origina um a múltiplos embriões adventícios ao redor do embrião sexual, fenômeno denominado embrionia adventícia. Este fenômeno trata de um mecanismo esporofítico de apomixia, em que não há necessidade da formação do saco embrionário para a diferenciação e o desenvolvimento do embrião, chamado então adventício, agâmico ou nucelar. Os embriões adventícios são geneticamente idênticos à planta da qual se originam (KOLTUNOV, 1993). Entretanto, alguns cultivares produzem sementes monoembriônicas, como as tangerineiras Clementina (C. clementina Hort. ex Tan.); o tangor Temple ( $\boldsymbol{C}$. sinensis x $C$ reticulata); o tangeleiro Lee $[\boldsymbol{C}$. reticulata $\mathrm{x}(\boldsymbol{C}$. tangerina Hort. ex Tan. x $\boldsymbol{C}$. paradisi)] e a grande maioria das toranjeiras $[\boldsymbol{C}$. maxima (Burm.) Merrill.]. Acredita-se que, nestes cultivares, o único embrião encontrado nas sementes é zigótico, portanto, portador de variabilidade genética, e pode ser híbrido, desde que resultante de polinização por outro cultivar (DAVIES \& ALBRIGO, 1994). Os cultivares monoembriônicos são úteis ao melhoramento genético para ausência de sementes.

O número de embriões encontrados nas sementes dos cultivares poliembriônicos é determinado por vários fatores, além do grau de poliembrionia típico de cada cultivar: a espécie polinizadora, o estado nutricional da planta e a disponibilidade hídrica, por exemplo, podem influenciar na formação dos embriões. Esta variação pode ocorrer entre frutos da mesma planta, em ramos diferentes, e em anos diferentes (RAMOS \& PASQUAL, 1992; PESCADOR, 1993).

Atualmente, o valor comercial dos frutos cítricos sem sementes torna necessário o desenvolvimento de cultivares partenocárpicos, principalmente de tangerineiras, para o cultivo no estado do Rio Grande do Sul, cujo clima e estrutura fundiária são propícios à citricultura de mesa (AMARO, 1984). O melhoramento genético, por sua vez, requer uma prévia caracterização de cultivares genitores potenciais.
O objetivo do trabalho foi analisar quatro cultivares de tangerineira quanto à produção de sementes e à poliembrionia, a fim de caracterizá-los enquanto genitores e inferir sobre a sua utilização no melhoramento genético, tendo em vista que três destes cultivares já são utilizados nos cruzamentos do programa de melhoramento genético para ausência de sementes no Departamento de Horticultura e Silvicultura da Universidade Federal do Rio Grande do Sul.

\section{MATERIAL E MÉTODOS}

Foram coletados frutos de plantas pertencentes à coleção de espécies e cultivares de citros do Setor de Horticultura da Estação Experimental Agronômica da Faculdade de Agronomia da Universidade Federal do Rio Grande do Sul, cultivada em solo podzólico vermelho-amarelo, no município de Eldorado do Sul, Rio Grande do Sul, Brasil, à latitude $30^{\circ} 39^{\prime} \mathrm{S}$ e longitude $51^{\circ} 06^{\prime} \mathrm{W}$. A coleta foi feita durante dez semanas a partir de 195 dias após a antese, período escolhido em função da fase em que PESCADOR (1993) obteve os melhores percentuais de germinação de embriões de laranjeira Cipó.

Foram retirados, aleatoriamente, frutos de três plantas do cultivar Caí (C. deliciosa), três plantas do cultivar Montenegrina $(\boldsymbol{C}$. deliciosa), três plantas do cultivar Poncã ( $\boldsymbol{C}$. reticulata) e de uma planta do cultivar King (C. nobilis), totalizando 244 frutos analisados. Cada fruto foi aberto com um corte superficial da casca e torção em torno do eixo. $\mathrm{O}$ diâmetro do fruto foi medido e registrado em milímetros. As duas metades do fruto foram espremidas manualmente numa bandeja e cada gomo foi esvaziado com uma espátula para a extração das sementes aderidas e das abortadas.

Anotaram-se o número de sementes viáveis (ou cheias) e o número de sementes inviáveis por fruto. Foram consideradas sementes inviáveis, vazias ou não desenvolvidas aquelas sem embrião no seu interior ou com embrião morto ou aquelas sementes de desenvolvimento insuficiente, de tamanho muito pequeno, mas ainda visível. Posteriormente, o peso de sementes viáveis de 48 frutos maduros foi registrado, em gramas, para uma caracterização das sementes.

As sementes consideradas viáveis foram submetidas à assepsia através de lavagem em água corrente com detergente, imersão em etanol $70 \%$ por 10 minutos, sob agitação, e em hipoclorito de sódio (NaOCL) 1\%, acrescido de três gotas por litro de detergente concentrado, sob agitação, por 15 minutos. Em seguida, as sementes permaneceram em água estéril a $35^{\circ} \mathrm{C}$ por 15 minutos. 
Na câmara de fluxo estéril, procedeu-se a retirada dos embriões a partir das sementes inteiras e secas. Utilizaram-se instrumentos autoclavados e flambados para abrir os integumentos e extrair os embriões, que eram imediatamente inoculados. O cultivo foi feito em frascos snap cap de diâmetro $6 \mathrm{~cm}$, altura $8 \mathrm{~cm}$ e volume $200 \mathrm{ml}$, contendo aproximadamente $15 \mathrm{ml}$ de meio de cultivo MT (MURASHIGE \& TUCKER, 1969) com 3\% de sacarose, pH 5,8 e 7g de ágar/L. Após a inoculação dos embriões de cada semente dentro de um frasco, ele era vedado e identificado. Os frascos foram mantidos em sala de crescimento a temperaturas de $26 \pm 3^{\circ} \mathrm{C}$ e fotoperíodo de 16 horas. Foram cultivadas ao todo 2167 embriões.

Completados 49 dias de cultivo in vitro, os frascos de cultivo foram abertos e os embriões foram removidos para a avaliação do seu número e crescimento. Foram registrados, separadamente, por semente, por fruto e por cultivar, o número total de embriões, o número de embriões que apresentou desenvolvimento in vitro e o número de embriões que não apresentou desenvolvimento. A contagem do número total de embriões por semente mostrou o grau de poliembrionia de cada um dos cultivares. A contagem do número de embriões que não germinou in vitro foi feita para quantificar a fração de embriões que nem mesmo in vitro encontram condições de germinação, indicando alguma deficiência na sua formação, seja pelo pequeno volume de reservas, seja pelas prováveis anormalidades genéticas e cromossômicas apontadas na literatura (OIYAMA, 1981; IWAMASA \& NITO, 1988).

Também foi registrada a ocorrência de embriões albinos, cujo crescimento in vitro foi semelhante ao dos embriões normais. As plântulas, oriundas destes embriões, foram submetidas à aclimatização junto com plântulas normais, para uma comparação do percentual de sobrevivência entre elas.

Os dados foram submetidos à análise da variância ponderada (GLM-SAS) e a significância da diferença entre as médias foi calculada pelo teste de Duncan em nível de $5 \%$ de probabilidade. entre estes valores. $5 \%$ de probabilidade.

\section{RESULTADOS E DISCUSSÃO}

Observou-se diferença significativa entre os cultivares, que formaram grupos distintos por espécie taxonômica, quanto ao número de sementes viáveis produzidas por fruto (tabela 1). O cultivar King apresentou um número de sementes viáveis significativamente maior que os demais (média de 24,5) e o cultivar Poncã foi o que apresentou menor número de sementes viáveis por fruto (média de $8,2)$. Os valores extremos encontrados de sementes viáveis por fruto foi de zero a 35 no cultivar Caí; seis a 20 no cultivar Montenegrina; dois a 15 no cultivar Poncã e 14 a 33 no cultivar King. O cultivar Caí distingüiu-se dos demais cultivares no que se referiu à produção de sementes inviáveis, produzindo uma média de 10,9 sementes inviáveis por fruto. Esta diferença não foi relatada na literatura. Não há qualquer observação a respeito de discrepâncias no número de sementes deste cultivar ou índices elevados de esterilidade, o que leva à hipótese de que tenha ocorrido alguma condição ambiental desfavorável à formação do saco embrionário e à embriogênese da nucela nos estágios iniciais da formação do fruto, tal como grande competição entre os botões florais ou deficiência hídrica.

Os valores extremos encontrados para o número de sementes inviáveis por fruto foi de zero a 21 em Caí; zero a 27 em Montenegrina; zero a 13 em Poncã e um a 16 em King. A contagem das sementes inviáveis oferece indícios a respeito do grau de abortamento de óvulo entre os cultivares ou de inviabilização do embrião por vários processos, dentre os quais fecundação por gametas não reduzi-

Tabela 1 - Diâmetro médio dos frutos $(\varnothing)$, número de sementes viáveis por fruto (NSV) e número de sementes inviáveis por fruto (NSI) dos quatro cultivares de tangerineira e as correlações

\begin{tabular}{|c|c|c|c|c|c|c|}
\hline \multirow[t]{2}{*}{ Cultivar } & \multirow[t]{2}{*}{$\varnothing(\mathrm{mm})$} & \multirow[t]{2}{*}{ NSV } & \multirow[t]{2}{*}{ NSI } & \multicolumn{3}{|c|}{ Correlações } \\
\hline & & & & NSVxNSI & $\varnothing \times \mathrm{xNS}$ & $\varnothing \times(\mathrm{NSV}+\mathrm{NSI})$ \\
\hline Caí & $55,64 \mathrm{~b}$ & $15,8 \mathrm{~b}$ & $10,9 \mathrm{a}$ & $-0,417 *$ & $+0,061 \mathrm{~ns}$ & $+0,187 \mathrm{~ns}$ \\
\hline Montenegrina & $47,20 \mathrm{c}$ & $14,0 \mathrm{~b}$ & $6,3 \mathrm{~b}$ & $-0,269^{*}$ & $-0,146 n s$ & $+0,100 \mathrm{~ns}$ \\
\hline Poncã & $54,22 \mathrm{~b}$ & $8,2 \mathrm{c}$ & $5,1 \mathrm{~b}$ & $+0,206 \mathrm{~ns}$ & $+0,192 \mathrm{~ns}$ & $+0,002 \mathrm{~ns}$ \\
\hline King & $66,33 \mathrm{a}$ & $24,5 \mathrm{a}$ & $5,1 \mathrm{~b}$ & $+0,009 \mathrm{~ns}$ & $+0,235 \mathrm{~ns}$ & $+0,123 \mathrm{~ns}$ \\
\hline Média geral & 53,67 & 13,8 & 7,3 & $-0,048 \mathrm{~ns}$ & $+0,254^{*}$ & $+0,290^{*}$ \\
\hline
\end{tabular}

Médias seguidas de letras iguais nas colunas não diferem entre si pelo teste de Duncan em nível de

*= coeficiente de correlação significativo; ns= coeficiente de correlação não significativo. 
dos ou irregularmente reduzidos, tendo em vista que alguns autores mencionaram a ocorrência de embriões inviáveis ou já abortados, com número cromossômico anormal, em sementes pequenas e vazias (OIYAMA, 1981; IWAMASA \& NITO, 1988).

A soma do número total de sementes (viáveis e inviáveis) pode oferecer indícios quanto ao número total de óvulos originalmente constituintes do ovário. Este valor apresentou diferença estatística significativa entre todos os cultivares, sendo maior em King $(29,6)$. Caí produziu em média 26,8, apesar de grande parte, em torno de $41 \%$, ter originado sementes inviáveis. Montenegrina e Poncã totalizaram 20,3 e 13,3, respectivamente.

O coeficiente de correlação entre o número de sementes viáveis e o número de sementes inviáveis foi negativo e significativo apenas em Caí e Montenegrina, indicando que o maior número de sementes inviáveis é concomitante ao menor número de sementes viáveis nestes dois cultivares (tabela 1).

O resultado da análise da variância ponderada indica diferença significativa no diâmetro dos frutos dos dois cultivares de $\boldsymbol{C}$. deliciosa. Tal diferença pode ser explicada pelo fato de Montenegrina ser bastante tardia, apresentando atraso no desenvolvimento do fruto, pois completa a maturação entre $1^{\mathrm{O}}$ de agosto e 15 de outubro na Depressão Central do Rio Grande do Sul (SARTORI et al., 1996).

Apesar de também ser tardia, King apresentou o diâmetro do fruto significativamente maior, mostrando a sua marcada característica de produzir frutos grandes já entre 195 e 265 dias após a antese. Além disso, King também se distingüe por alcançar a coloração de maturação da casca relativamente cedo em relação à maturação do interior do fruto (HODGSON, 1967), que se completa entre 15 de setembro e 31 de outubro na Depressão Central do Rio Grande do Sul (SARTORI et al., 1996).

Os dois cultivares precoces, Caí e Poncã, não apresentaram diferenças quanto ao diâmetro do fruto, indicando que esta característica é dependente do estado de maturação do fruto e que o tamanho dos frutos deve ser comparado entre as fases de desenvolvimento correspondentes no desenvolvimento dos frutos. O cultivar Caí probabilidade. atinge o ponto de maturação entre $1^{\circ}$ de maio e 30 de julho na Depressão Central do Rio Grande do Sul (SARTORI et al., 1997).

Os valores extremos, mínimo e máximo, encontrados no diâmetro de fruto foi de 37 e $71 \mathrm{~mm}$ em Caí; 39 e 63mm em Montenegrina; 43 e $68 \mathrm{~mm}$ em Poncã; e 52 e $78 \mathrm{~mm}$ em King. O resultado da análise de correlação não indicou um coeficiente de correlação significativo, tanto entre diâmetro e número de sementes viáveis quanto na correlação entre diâmetro e soma de sementes viáveis e inviáveis. Isto indica que, nestas tangerinas, não ocorreram as mesmas correlações significativas mencionadas por FROST \& SOOST (1968) para variedades como as tangerinas Frua e Clementina e os tangelos Orlando e Minneola. A análise de correlação entre o número de sementes e o diâmetro dos frutos foi significativa apenas na análise do total dos cultivares, em que se teve um grande número de repetições.

Quanto ao número total de embriões por semente (tabela 2), observaram-se diferenças significativas entre espécies taxonômicas. O cultivar Poncã produziu um número médio de embriões por semente, significativamente, maior que os demais; Caí e Montenegrina produziram um número intermediário; e o cultivar King mostrou-se menos poliembriônico.

Os embriões de King, normalmente apresentaram uma disposição na semente diferente dos demais cultivares. As sementes de King, normalmente, apresentam um embrião de tamanho grande, que ocupa quase todo o espaço interno da semente, com a presença de poucos e pequenos embriões na extremidade relativa à micrópila. Os cultivares Caí, Montenegrina e Poncã apresentaram embriões de tamanho intermediário entre o maior e o menor deles.

Tabela 2 - Peso médio da semente, número médio de embriões por semente, percentual de sementes monoembriônicas e percentual de embriões germinados e não germinados in vitro dos quatro cultivares de tangerineira.

\begin{tabular}{|c|c|c|c|c|c|}
\hline \multirow{2}{*}{ Cultivar } & \multirow{2}{*}{$\begin{array}{c}\text { Peso da } \\
\text { semente }(\mathrm{g})\end{array}$} & \multirow{2}{*}{$\begin{array}{l}\text { № médio de } \\
\text { embriões/sem. }\end{array}$} & \multirow{2}{*}{$\begin{array}{c}\text { \% de sementes } \\
\text { monoembriônicas }\end{array}$} & \multicolumn{2}{|c|}{$\%$ de embriões } \\
\hline & & & & Germinados & Não-Germinados \\
\hline Caí & $0,13 \mathrm{c}$ & $5,74 \mathrm{~b}$ & 7,47 & $88,61 \mathrm{ab}$ & $11,43 \mathrm{bc}$ \\
\hline Montenegrina & $0,17 \mathrm{~b}$ & $5,65 \mathrm{~b}$ & 5,87 & $90,60 \mathrm{a}$ & $9,49 \mathrm{c}$ \\
\hline Poncã & $0,17 \mathrm{~b}$ & $7,66 \mathrm{a}$ & 3,15 & $82,61 \mathrm{c}$ & $17,45 \mathrm{a}$ \\
\hline King & $0,20 \mathrm{a}$ & $3,24 \mathrm{c}$ & 20,36 & $87,28 \mathrm{~b}$ & $12,72 b$ \\
\hline
\end{tabular}

Médias seguidas de letras iguais nas colunas não diferem entre si pelo teste de Duncan em nível de 5\% de

Ciência Rural, v. 29, n. 3, 1999. 
Poncã apresentou diferença significativa em relação às demais, à medida que se mostrou a mais poliembriônica, enquanto produziu menor número de sementes por fruto, em contraste com King, que se mostrou menos poliembriônica, mas produziu o maior número de sementes por fruto. Os números extremos, mínimo e máximo, de embriões encontrados dentro de uma semente viável foi de um a 23 em Caí; um a 19 em Montenegrina; um a 32 em Poncã; e um a doze em King.

O número de embriões por semente produzidos mediante polinização aberta destes cultivares é normalmente diferente do número de embriões produzidos mediante polinização dirigida. BASTIANEL et al. (1997) obtiveram uma média de 3,31 embriões por semente do cultivar Montenegrina sob polinização dirigida com o cultivar King, a partir de um total de 80 sementes.

A ocorrência de sementes monoembriônicas foi observada nos quatro cultivares, com valor inversamente proporcional ao de embriões por semente. O cultivar Poncã, mais poliembriônico, apresentou menor proporção de sementes monoembriônicas e o cultivar King, menos poliembriônico, apresentou uma proporção de sementes monoembriônicas relativamente alta. Desta forma, os cultivares apresentaram número de embriões por semente significativamente diferentes, resultado que concorda com BOWMAN et al. (1995), os quais afirmaram que a produção de embriões nucelares difere grandemente entre espécies cítricas.

A análise da variância ponderada demonstrou que houve diferença do número de embriões por semente dos quatro cultivares entre algumas semanas de coleta. Entretanto, não houve efeito da semana sobre o percentual de embriões germinados in vitro, indicando que, a partir de 195 dias após a antese, os embriões mostram-se suficientemente desenvolvidos para a germinação e que fatores metodológicos e genéticos tiveram maior influência sobre a percentagem de embriões germinados. A avaliação dos embriões quanto à percentagem de germinação (tabela 2) mostrou que o cultivar mais poliembriônico, Poncã, apresentou o menor percentual de embriões germinados in vitro, em torno de $82,61 \%$, diferenciandose de todas os demais.

A característica peso de sementes também mostrou diferenças entre cultivares (tabela 2). Caí apresentou sementes significativamente mais leves que as demais. Coincidentemente, este cultivar também apresentou maior número de sementes inviáveis. O cultivar King apresentou sementes mais pesadas em comparação com os demais cultivares, comprovando que o peso da semente não está ligado ao maior número de em- briões, pois este cultivar mostrou-se o menos poliembriônico.

Os resultados demonstraram que o número de embriões formados por semente não determina necessariamente o peso da semente. $\mathrm{O}$ maior tamanho de sementes não indica um alto grau de poliembrionia, indicando que, para estes cultivares, é inviável a proposta de BOWMAN et al. (1995) de que o tamanho da semente de citros, bem como a sua forma, podem permitir a previsão da emergência do embrião zigótico.

O percentual de embriões que deu origem a plântulas albinas (tabela 3) foi bastante inferior no cultivar King, com média de 2,21\%, enquanto os demais cultivares apresentaram percentuais sempre superiores a 4,00\%. O número de embriões albinos por semente variou conforme o número total de embriões da semente. As plântulas albinas submetidas à aclimatização mostraram-se incapazes de adaptação à condição autotrófica, morrendo em poucos dias.

Não foram encontrados registros na bibliografia quanto à presença de albinos na progênie dos citros, o que dificulta a análise destes resultados. Pode-se admitir que ocorram anormalidades na formação do embrião a partir do tecido nucelar, mostrando, desta forma, que a embriogênese nucelar pode originar indivíduos diferentes da planta de origem, não apenas no que se refere às variações no

Tabela 3 - Número e percentual de embriões albinos por semente dos quatro cultivares de tangerineira

\begin{tabular}{|c|c|c|c|c|c|}
\hline \multirow{2}{*}{ Cultivar } & & \multicolumn{3}{|c|}{ Embriões por semente } & \multirow{2}{*}{$\begin{array}{l}\text { Desvio } \\
\text { Padrão }\end{array}$} \\
\hline & & $\underset{\text { o mínim }}{\text { mam }}$ & médio & máxim & \\
\hline \multirow[t]{2}{*}{ Caí } & $\begin{array}{l}\mathrm{N} \\
\underline{0}\end{array}$ & 00 & $b^{0,16}$ & 12 & 0,62 \\
\hline & $\%$ & 0,00 & $4,03 \mathrm{a}$ & 100,00 & 14,75 \\
\hline \multirow{2}{*}{$\begin{array}{l}\text { Montenegrin } \\
\text { a }\end{array}$} & $\mathrm{N}$ & 00 & 0,17 & 7 & 0,58 \\
\hline & $\%$ & 0,00 & " $4,29 \mathrm{a}$ & 100,00 & 14,46 \\
\hline \multirow[t]{2}{*}{ Poncã } & $\begin{array}{l}\mathrm{N} \\
\underline{0}\end{array}$ & 00 & $0,28 \mathrm{a}$ & 11 & 0,73 \\
\hline & $\%$ & 0,00 & $4,24 \mathrm{a}$ & 100,00 & 14,68 \\
\hline \multirow[t]{2}{*}{ King } & $\begin{array}{l}\mathrm{N} \\
\underline{0}\end{array}$ & 00 & $c^{0,05}$ & 1 & 0,69 \\
\hline & $\%$ & 0,00 & $2,21 \mathrm{a}$ & 100,00 & 14,27 \\
\hline
\end{tabular}

Médias seguidas de letras iguais na coluna não diferem entre si pelo teste de Duncan em nível de 5\% de probabilidade. 
número cromossômico e às variações no nível de ploidia mencionadas pela bibliografia (ESEN \& SOOST, 1972; IWAMASA \& NITO, 1988).

De maneira geral, observaram-se várias similaridades entre os dois cultivares de $\boldsymbol{C}$. deliciosa, Caí e Montenegrina, no que se referiu à produção de sementes e à poliembrionia, indicando a possibilidade de Montenegrina ter se originado de Caí, conforme proposto por MARODIN (1987). Entretanto, Caí apresentou uma diferença saliente no que se referiu à viabilidade de sementes, produzindo número significativamente grande de sementes inviáveis. Os cultivares apresentaram, em comum, alta fertilidade, e as três espécies taxonômicas mostraram diferenças significativas na produção de sementes e na poliembrionia.

\section{CONCLUSÃO}

Os cultivares Caí, Montenegrina, Poncã e King produzem sementes poliembriônicas, havendo ocasional ocorrência de monoembrionia, destacadamente em King. O peso de sementes é uma característica varietal e não serve como indicativo do número total de embriões por semente entre os cultivares estudados. Embriões albinos ocorrem na progênie dos quatro cultivares, constituindo uma parte ou a totalidade dos embriões da semente e originando plantas inviáveis.

\section{AGRADECIMENTOS}

Este trabalho foi executado no Laboratório de Biotecnologia em Horticultura - DHS - UFRGS, com o apoio financeiro do $\mathrm{CNPq}$

\section{REFERÊNCIAS BIBLIOGRÁFICAS}

AGUSTI, M.F., ALMELA, V.O., AZNAR, M.A. et al. Desarrollo y tamanõ final del fruto en los agrios. Valencia: Generalitat Valenciana, 1995. 71p.

AMARO, A.A. Citriculture in Brazil. In: INTERNATIONAL CITRUS CONGRESS, 5, São Paulo, 1984. Proceedings.. São Paulo, International Society of Citriculture, 1987, v.1, p. XXIII-XXVI.

BASTIANEL, M., DORNELLES, A.L.C., SCHWARZ, S.F. et al. Resgate in vitro de embriões de tangerineiras (Citrus sp.) Revista Brasileira de Genética, Ribeirão Preto, v. 30, n. 3, p. $181,1997$.

BOWMAN, K.D., GMITTER JUNIOR, F.G., HU, X Relationships of seed size and shape with polyembriony and the zygotic or nucellar origin of Citrus spp. seedlings. HortScience, Alexandria, v. 60, n. 6, p. 1279-1282, 1995.
DAVIES, F.S., ALBRIGO, L.G. Crop Production Science in Horticulture 2: Citrus. Wallingford: CAB International, 1994. $254 \mathrm{p}$

ESEN, A., SOOST, R.K. Tetraploid progenies from $2 \mathrm{xx} 4 \mathrm{x}$ crosses of Citrus and their origin. Journal of the American Society for Horticultural Science, Alexandria, v. 97, n. 3, p. 410-414, 1972.

FROST, H.B., SOOST, R.K. Seed Reproduction: Development of gametes and embryos. In: REUTHER, W., BATCHELOR, L.D., WEBBER, H.J. The Citrus industry. Berkeley: University of California, 1968. v. 2, p. 290-324.

HODGSON, R.W. Horticultural varieties of Citrus. In: REUTHER, W., BATCHELOR, L.D., WEBBER, H.J.(Eds) The Citrus industry. Berkeley: University of California, 1967. v. 1, p. 431-591.

IWAMASA, M., NITO, N. Cytogenetics and the evolution of modern cultivated Citrus. In: INTERNATIONAL CITRUS CONGRESS, 6, Tel Aviv, 1988. Proceedings... Tel Aviv, International Society of Citriculture, 1988, v. 1, p. 265-275.

KOLTUNOV, A.M. Apomixis: embrio sacs and embryos formed without meiosis or fertilization in ovules. The Plant Cell, Maryland, v. 5, p. 1425-1437, 1993.

MARODIN, G.A.B. Raleio químico e manual de frutinhos em tangerineira (Citrus deliciosa Tenore) cv. 'Montenegrina'. Porto Alegre, 1987. 124p. Dissertação (Mestrado em Fitotecnia) - Faculdade de Agronomia, Universidade Federal do Rio Grande do Sul, 1987.

MURASHIGE, T., TUCKER, D.P.H. Growth factor requeriments of citrus tissue culture. In: INTERNATIONAL CITRUS CONGRESS, 1, Riverside, 1969. Proceedings... Riverside, International Society of Citriculture, 1969, v. 3, p. 1151-1161.

OIYAMA, I.. A technique for chromosome observation in root tip cells of Citrus. Bulletin Fruit Tree Research Station, (S.1.), v. 3, p. 1-7, 1981 .

PESCADOR, R. Cultivo de embriões de laranjeira 'Cipó' (Citrus sinensis Osb.) in vitro e uso de padrões isoenzimáticos na identificação dos Seedlings zigóticos e nucelares. Porto Alegre, RS, 1993. 96p. Dissertação (Mestrado em Fitotecnia) - Faculdade de Agronomia, Universidade Federal do RioGrande do Sul, 1993.

RAMOS, J.D., PASQUAL, M. Alterações na poliembrionia e identificação do híbrido em sementes de limão 'Cravo' obtidas de cruzamentos com Poncirus trifoliata (L.) Raf. Pesquisa Agropecuária Brasileira, Brasília, v. 27, n. 3, p. 423-427, 1992.

SARTORI, I.A., RECKZIEGEL, V.P., PEZZI, E.J.S. $\boldsymbol{e}$ t al Avaliação de épocas de maturação de tangerineiras para a Depressão Central do RS. In: SALÃO DE INICIAÇÃO CIENTÍfICA, 8, 1996, Porto Alegre. Resumos... Porto Alegre: UFRGS - PROPESP, 1996. p. CA118.

SARTORI, I.A., PEZZI, E.J.S., SCHWARZ, S.F. et al. Épocas de maturação e colheita de tangerineiras para a Depressão Central do RS. In: SALÃO DE INICIAÇÃO CIENTÍFICA, 8, 1997, Porto Alegre. Resumos... Porto Alegre: UFRGS PROPESP, 1997. p. CA105. 